\title{
COINTEGRATION, PRICE-ADJUSTMENT DELAYS, AND OPTIMAL HEDGE RATIO IN THE PRECIOUS METAL MARKETS
}

\begin{abstract}
Hirofumi Nishi
Corresponding Author: Hirofumi Nishi, Robbins College of Business and Entrepreneurship, Fort Hays State University, Hays, Kansas USA $\mathbf{m}+(785)$ 628-5337 $\square \underline{\text { h n nishi@fhsu.edu }}$
\end{abstract}

\begin{abstract}
Firms seeking to apply hedge accounting treatment under the Accounting Standards Codification Topic 815 must demonstrate higher hedge effectiveness, for which the regression analysis is commonly used as a testing method. An autoregressive distributed lag (ARDL) model is adopted in this article to examine the hedge effectiveness in the presence of a long-run cointegrating relationship between spot and futures prices while spot contracts are traded far less frequently. Using precious metal market data, our study empirically demonstrates that a hedge ratio estimated with a conventional OLS model tends to be downwardly biased. It is also shown that whether this omitted-variable bias is observable depends on the liquidity in a futures market.
\end{abstract}

Keywords: Commodity prices; Hedge accounting; Cointegration; Infrequent trading

\section{Introduction}

For both firms and investors, large earnings fluctuations associated with the derivative contracts used for hedging purposes are not desirable. In order to mitigate the earnings impact, the Accounting Standards Codification (ASC) Topic 815 issued by the Financial Accounting Standards Board (FASB) allows the gains and losses of derivatives to be combined in the same period with the gains and losses of the underlying hedged assets. Firms seeking to apply this special hedge accounting treatment must demonstrate the effectiveness of the hedge although the choice of the testing methodology is left to firms' discretion. One of the most commonly-used methods is the regression analysis, where the slope coefficient represents the optimal hedge ratio (i.e., the quantity of hedging instrument). ${ }^{1}$ In this approach, the hedge effectiveness is generally considered high if the coefficient of determination, or R-squared, is 0.80 or greater.

Since Johnson (1960) introduced the portfolio theory into the study of hedging strategy, the optimal hedge ratio has been defined as the ratio of the covariance between the changes in spot and futures prices and the variance of the futures price changes. Ederington (1979), building on the foundation laid out by Johnson (1960), measures the effectiveness of a hedging strategy as the percent reduction in the variance between the hedged return and the unhedged return. More recent studies, however, have pointed out that the optimal hedge ratio estimation using conventional ordinary least squares (OLS) model does not necessarily incorporate all available information and therefore suffers from possible information inefficiency. While Myers and Thompson (1989) propose adding lagged spot and futures prices to a hedge ratio estimation, Viswanath (1993) shows that adding the spot-futures basis makes the hedge ratio estimate closer to unity than the conventional OLS estimate for most of the hedging

1 Another commonly used approach is the dollar offset method with the $80 \%-125 \%$ rule. 
durations. ${ }^{2}$ Based on the analysis of the relationship between the basis and a futures contract maturity, Castelino (1992) shows that the minimum-variance hedge ratio increases as the hedge-lifting date approaches the contract maturity.

Information inefficiency in the OLS model is closely related to two econometric issues, one of which is the existence of a long-term relationship between spot and futures prices. The long-run equilibrium between two or more time series, the concept introduced by Granger (1981) and known as cointegration, often exists in the commodity markets. The effect on the hedge ratio estimate of the omission of a spot-future cointegration has been studied from various perspectives. Ghosh (1993) and Kroner and Sultan (1993) both suggest that incorporating the long-run cointegrating relationship between asset prices significantly improve the optimal hedge ratio estimate. Lien (2004) theoretically assesses the effect of a long-run relationship between spot and futures prices and suggests that omitting cointegration leads to a smaller hedge ratio. In contrast, Chen et al. (2004), based on the data of 25 different commodities, conclude that the conventional OLS hedge ratio estimate ultimately approaches unity if the hedge horizon is sufficiently long. ${ }^{3}$ Likewise, Juhl et al. (2012) conclude that including the error-correction term to account for cointegration does not significantly improve the estimation performance for a long hedge horizon. The relationship between the hedge effectiveness and the hedge horizon is also discussed in section 3 of this article.

The second issue affecting the hedge effectiveness in the conventional OLS approach is infrequent trading, or low transaction volumes, of certain commodity contracts. The previous studies, thin trading has been investigated primarily in equity or bond markets. For example, Scholes and Williams (1977) and Dimson (1979) both examine the beta estimated by the capital asset pricing model (CAPM) in the presence of nonsynchronous trading and provide adjusted beta estimates. Lo and MacKinlay (1990a) utilize the data from various stocks grouped by firm size and generalize the models on thin trading by using stochastic intervals between trades. Using the data of thinly-traded stocks of Finnish firms, Luoma et al. (1993) conclude that the estimated error-correction term is highly dependent on the trading frequency of the underlying stock. ${ }^{4}$ Wilkinson et al. (1999) analyse the New Zealand and Australian debt securities and argue that the lead-lag relations caused by infrequent trading do not impact hedge effectiveness.

The present article aims to expand the literature on commodity hedging by connecting two econometric issues: cointegration between spot and futures prices and infrequent trading in spot and futures markets. Despite a voluminous literature on liquidity in capital markets, little statistical work has been done in the context of commodity hedging and on how infrequent trading of a commodity contract affects the omitted-variable bias in the presence of spot-futures cointegration. Though seemingly unrelated, these issues are closely relevant to each other. The existence of a long-term equilibrium relationship between two prices implies that at least one of them must be pulled back to the equilibrium before deviating from it too far or too long. This means that, if the transaction frequency of a spot contract is significantly lower than that of a futures contract (i.e., a futures market is far more liquid than a spot market), the bias caused by ignoring their cointegrating relationship could be exacerbated. In order to test this effect, our study specifically utilizes the data from the precious metal markets where spot and futures contracts are traded at very different frequencies, yet their prices are still cointegrated. The autoregressive distributed lag (ARDL) model is used to estimate the optimal hedge ratio for cointegrated commodity price series while a long-run cointegrating relationship between the price series is tested with the ARDL bounds test procedure introduced by Pesaran et al. (2001).

\footnotetext{
2 Viswanath (1993) notes that this approach is only correct if the spot-futures convergence is guaranteed. Such convergence often fails to take place in agricultural markets possibly because of the design of the exchange's delivery system (Aulerich et al., 2011).

3 Also see Howard and D'Antonio (1991) and Benet (1992) for the studies on the relationship between the hedge period and hedging effectiveness.

${ }_{4}^{4}$ Luoma et al. (1993) and Chen et al. (2004) both utilize the model that only includes the contemporaneous and the one-period-lagged values of each variable (i.e., ARDL $(1,1))$.
} 
Briefly highlighting the results in this article, our study empirically demonstrates that an ARDL-adjusted estimate of a spot-futures hedge ratio tends to be higher than a conventional OLS estimate. This implies that an OLS estimate is downwardly biased when a cointegrating relationship between two prices is ignored. This is consistent to Lien's (2004) proposition. Our result also indicates that bias caused by the omission of a long-run equilibrium relation is associated with the liquidity in a futures market. We compare the daily transaction volumes of futures contracts across commodities, and it appears that the omittedvariable bias becomes observable only when a futures market is relatively active.

The remainder of this paper is organized as following. Section 2 describes the data used in this study and provides a brief description of the conventional OLS-based and the ARDL-adjusted hedge ratios. Various econometric biases in the hedge ratio estimation are also discussed. Section 3 presents the result of the ARDL bounds test for cointegration followed by the comparison of the OLS and the ARDL-based hedge ratios. Section 4 provides the summary.

\section{Data and Methodologies}

\subsection{Data and Time-Series Structures}

The daily spot price data for the period between January 2006 and June 2016 are collected from the London Bullion Market Association (LBMA). The LBMA gold auction takes place twice a day, at 10:30 a.m. and 3:00 p.m. London time, and administered by ICE Benchmark Administration (IBA). The LBMA silver auction takes place once a day at 12:00 noon and is operated by the CME Group and administered by Thomson Reuters. Lastly, the LBMA platinum and palladium auctions take place twice a day, at 9:45 a.m. and 2:00 p.m., and are administered by the London Metal Exchange (LME). For gold, platinum, and palladium, the prices observed in the afternoon session are used in this study.

The daily price settlement data of the Commodity Exchange Inc. (COMEX) gold and silver futures contracts and the New York Mercantile Exchange (NYMEX) palladium and platinum futures contracts during the sample period come from the Bloomberg Professional Service. The settlement prices, instead of intra-day futures prices, are used due to their transparency. Note that there are up to several hours of difference between the afternoon session of a LBMA auction (12:00 p.m., 2:00 p.m., or 3:00 p.m. London time) and the settlement of a COMEX/NYMEX futures contract (1:30 p.m. EST). In practice, however, this time lag has limited impact on a firm's hedging activities as a hedge horizon is typically set longer than one day. Moreover, the adjustment between spot and futures prices usually takes longer than several trading days, making several hours of difference relatively insignificant. ${ }^{5}$

Our study uses the prices of the second nearest-to-delivery futures contracts. That is, once the second month becomes the front month, the data rolls over to the next contract month. The second nearest-todelivery contracts are used because the transaction volume of a metal futures contract tends to decline sharply after it becomes the nearest-to-delivery contract. This also implies that the second nearest-todelivery contracts are most frequency traded. The weekly data are retrieved from every Tuesday; if Tuesday is not available in one or both the spot and futures markets (e.g., non-trading day), then Wednesday is used. If both Tuesday and Wednesday are unavailable, then Monday is used. This strategy ensures that each spot/futures price change pair is encompassed about seven days. The monthly contract data are retrieved on the first trading day of each month. 6 Table 1 presents the statistics of the daily spot prices and the daily second nearest-to-delivery futures contract settlement prices observed during the sample period.

\footnotetext{
${ }^{5}$ An unreported linear Granger-causality test suggests that, for all the commodities, the daily futures price returns lead the daily spot price returns for up to 12 trading days.

6 The price series for one-month and one-week hedge periods are constructed as described here in order to avoid auto-correlated residuals caused by overlapping data bias.
} 
Table 1: Daily Spot and Futures Precious Metal Prices: January 2006 - June 2016

A single asterisk $\left({ }^{*}\right)$ indicates the $5 \%$ level of significance and a double asterisk $\left({ }^{* *}\right)$ means the $1 \%$ level of significance or better for the Jarque-Bera (JB) test on the hypothesis that the variable is normally distributed. The third column indicates the number of LBMA auctions held per day (spot market) and the average daily transaction volume of the second nearest futures contract during the sample period (futures market).

\begin{tabular}{|c|c|c|c|c|c|c|c|c|c|}
\hline & \multicolumn{2}{|r|}{ Freq. } & \multicolumn{4}{|c|}{ Price } & \multicolumn{3}{|c|}{ Test for normality } \\
\hline & Obs. & / Vol. & Min & Max & Mean & Std. Dev. & Skewness & Kurtosis & JB test \\
\hline \multicolumn{10}{|l|}{ Gold } \\
\hline LBMA Spot & 2598 & 2/day & 520.75 & 1891.00 & 1147.92 & 342.23 & 0.0056 & 2.0967 & $88.34^{* *}$ \\
\hline COMEX Futures & 2598 & 131,022 & 527.80 & 1889.00 & 1148.38 & 341.86 & 0.0064 & 2.0966 & $88.36^{* *}$ \\
\hline \multicolumn{10}{|l|}{ Platinum } \\
\hline LBMA Spot & 2598 & 2/day & 756.00 & 2276.00 & 1382.39 & 289.34 & 0.2023 & 2.6107 & $34.12^{* *}$ \\
\hline NYMEX Futures & 2598 & 7,748 & 760.00 & 2275.00 & 1381.43 & 288.68 & 0.2010 & 2.6334 & $32.03^{* *}$ \\
\hline \multicolumn{10}{|l|}{ Palladium } \\
\hline LBMA Spot & 2598 & 2/day & 168.00 & 901.00 & 541.07 & 198.80 & -0.1422 & 1.6746 & $198.91^{* *}$ \\
\hline NYMEX Futures & 2598 & 3,740 & 167.00 & 900.00 & 539.80 & 195.80 & -0.1441 & 1.6914 & $194.37^{* *}$ \\
\hline \multicolumn{10}{|l|}{ Silver } \\
\hline LBMA Spot & 2598 & 1/day & 8.83 & 48.70 & 19.74 & 7.83 & 1.0304 & 3.1453 & $461.97^{* *}$ \\
\hline COMEX Futures & 2598 & 43,433 & 8.79 & 47.53 & 19.72 & 7.79 & 1.0111 & 3.0772 & $443.31^{* *}$ \\
\hline
\end{tabular}

\subsection{Conventional OLS and ARDL-Adjusted Hedge Ratios}

Suppose that $\mathrm{S}_{t}$ and $\mathrm{F}_{t}$ represent the spot price of a certain commodity and the corresponding futures price, both at time t, respectively. Following Chen et al. (2004) and Juhl et al. (2012), our study applies the OLS regression model to first-differenced price series as following.

$$
\Delta \mathrm{S}_{t}=\alpha+\beta_{\mathrm{OLS}} \Delta \mathrm{F}_{t}+\varepsilon_{t}
$$

where $\Delta \mathrm{S}_{t}=\mathrm{S}_{t}-\mathrm{S}_{t-1}$ and $\Delta \mathrm{F}_{t}=\mathrm{F}_{t}-\mathrm{F}_{t-1} \cdot \beta_{\mathrm{OLS}}$ is the optimal hedge ratio between a spot contract and a futures contract and it is estimated as the ratio of the covariance between the changes in spot and futures prices to the variance of the futures price changes.

$$
\widehat{\beta}_{\mathrm{OLS}}=\frac{\operatorname{Cov}\left(\Delta \mathrm{S}_{t}, \Delta \mathrm{F}_{t}\right)}{\operatorname{Var}\left(\Delta \mathrm{F}_{t}\right)}
$$

One statistical problem in this approach is that, especially in commodity markets, the transaction frequencies of spot contracts are often far less than those of the corresponding futures contracts. For example, the LBMA gold auction takes place twice a day at 10:30 a.m. and 3:00 p.m. in London time. Once the net volume of the buy and sell orders falls within the pre-determined tolerance level of imbalance, 10,000 ounces, then all the volume becomes tradeable at the initial price set by the chairperson. ${ }^{7}$ The transaction frequencies in this system are clearly far less than those in the futures contracts at COMEX or NYMEX. In addition, the spot contracts typically have less transaction volumes than actively-traded futures contracts. ${ }^{8}$ Infrequent trading in a spot market lowers the covariance estimate in Equation (2), which subsequently lowers the hedge ratio estimate.

\footnotetext{
7 If the imbalance exceeds the tolerance level, the auction restarts with a revised auction price and continues until the equilibrium price is set.

8 For example, 2.958 million COMEX gold futures contract ( $\approx 295.8$ million troy ounces) were traded during January 2016 while the total volume transacted at the LBMA in the same period was 5.701 million troy ounces (bids and asks combined). This represents a difference of 52-to-I.
} 
Perhaps, a more critical problem in the conventional OLS method is that it does not take into account the possibility that spot and futures prices are mutually cointegrated. As shown by the previous studies, the OLS approach is likely to suffer from omitted-variable bias if there exists a long-term equilibrium relationship between spot and futures prices. In contrast, the ARDL model allows the effect of an independent variable on the dependent variable to be distributed over time while lagged values of the dependent variable itself can also be additional regressors. In other words, there will be the immediate effect of a variable at time $t$ followed by delayed effects taking place in later periods. Suppose the $\operatorname{ARDL}(p, q)$ model with an unrestricted intercept and time trend as following.

$$
\mathrm{S}_{t}=\mathrm{c}_{0}+\mathrm{c}_{1} t+\sum_{\mathrm{i}=1}^{\mathrm{p}} \Phi_{\mathrm{i}} \mathrm{S}_{t-\mathrm{i}}+\sum_{\mathrm{i}=0}^{\mathrm{q}} \beta_{\mathrm{i}} \mathrm{F}_{t-\mathrm{i}}+\mu_{t}
$$

The lag orders for the dependent and independent variables in this model are equal to $p$ and $q$, respectively. Following Pesaran and Shin (1998), the equation can be transformed into the errorcorrection form as following.

$$
\Delta \mathrm{S}_{t}=\mathrm{c}_{0}+\mathrm{c}_{1} t+\sum_{\mathrm{i}=1}^{\mathrm{p}-1} \lambda_{\mathrm{S}, \mathrm{i}} \Delta \mathrm{S}_{t-\mathrm{i}}+\sum_{\mathrm{i}=0}^{\mathrm{q}-1} \lambda_{\mathrm{F}, \mathrm{i}} \Delta \mathrm{F}_{t-\mathrm{i}}+\Phi(1)\left(\mathrm{S}_{t-1}-\theta \mathrm{F}_{t-1}\right)+\mu_{t}
$$

where

$$
\theta=\frac{\sum_{i=0}^{\mathrm{q}} \beta_{\mathrm{i}}}{\Phi(1)}
$$

and

$$
\Phi(1)=1-\sum_{\mathrm{i}=1}^{\mathrm{p}} \Phi_{\mathrm{i}}
$$

The set of $\lambda_{\mathrm{F}, \mathrm{i}}$ collectively reflects the effect of short-term changes in the futures price on the spot price change. $\Phi(1)\left(\mathrm{S}_{t-1}-\theta \mathrm{F}_{t-1}\right)$ is referred to as the error-correction term; $\theta$ indicates the long-run equilibrium relation between the spot and futures prices while $\Phi(1)$ represents the speed of adjustment to a temporary deviation from such equilibrium.

The ECM derived from the ARDL approach has advantages relative to the two-step error correction model (ECM) shown by Engle and Granger (1987). First, the ARDL approach is a non-residuals-based method that yields the short-run and long-run parameter estimates in a single equation at a time. In addition, the ARDL bounds test procedure can be applied irrespective of whether the regressors are purely 1(0), purely 1(1), or mutually cointegrated. In contrast, conventional cointegration testing procedures, such as the Engle-Granger (1987) test and Johansen's (1988) rank test, require all the variables to be integrated of the same order and therefore pre-testing of unit roots is necessary. ${ }^{9}$ The ARDL bounds test also provides robust results with a relatively small sample size $(<80)$ when using the critical value bounds calculated by Narayan (2005). ${ }^{10}$

\footnotetext{
9 It is still advisable to do so in order to confirm that none of the variables is integrated of higher order.

10 Given relatively large sample sizes, this study utilizes the critical value bounds provided by Pesaran et al. (2001).
} 


\section{Empirical Results and Discussion}

\subsection{ARDL Bounds Test for Cointegration}

The first step of our analysis is to verify the existence of a long-run relationship between spot and futures prices in each of the precious metal markets. The ARDL bounds test is utilized for this purpose. As mentioned in sub-section 2.2, prior knowledge about the order of integration of each variable is not necessary in this approach. The optimal lag orders for spot and futures prices, denoted as $\mathrm{p}^{*}$ and $\mathrm{q}^{*}$ respectively, are determined using the Akaike Information Criterion (AIC) with the maximum lag order of 12.

\section{Table 2: ARDL Bounds Test for Cointegration between Spot and Futures Prices}

The optimal lag orders for the first-differenced spot price $\left(=p^{*}\right)$ and the first-differenced futures price $\left(=q^{*}\right)$ are determined with the Akaike Information Criterion (AIC). The F-test is performed against the joint hypothesis that the coefficients of the contemporaneous and lagged futures prices are collectively zero and the speed-of-adjustment coefficient is zero. The t-test is performed against the null hypothesis of zero speed-of-adjustment coefficient. The bounds on the critical values obtained from Pesaran et al. (2001). A single asterisk (*) and a double asterisk (**) indicate a significance level of $5 \%$ and $1 \%$, respectively.

$$
\Delta \mathrm{S}_{t}=\mathrm{c}_{0}+\mathrm{c}_{1} t+\sum_{\mathrm{i}=1}^{\mathrm{p}-1} \lambda_{\mathrm{S}, \mathrm{i}} \Delta \mathrm{S}_{t-\mathrm{i}}+\sum_{\mathrm{i}=0}^{\mathrm{q}-1} \lambda_{\mathrm{F}, \mathrm{i}} \Delta \mathrm{F}_{t-\mathrm{i}}+\Phi(1)\left(\mathrm{S}_{t-1}-\theta \mathrm{F}_{t-1}\right)+\mu_{t}
$$

\begin{tabular}{llccc}
\hline Commodity & Data frequency & ARDL $\left(\mathbf{p}^{*}, \mathbf{q}^{*}\right)$ & F-statistic & t-statistic \\
\hline Gold & Daily & $(11,12)$ & $77.351^{* *}$ & $-12.438^{* *}$ \\
& Weekly & $(12,5)$ & $74.405^{* *}$ & $-12.199^{* *}$ \\
& Monthly & $(1,1)$ & $70.284^{* *}$ & $-11.855^{* *}$ \\
\hline Platinum & Daily & $(12,12)$ & $52.877^{* *}$ & $-10.275^{* *}$ \\
& Weekly & $(1,1)$ & $4179.755^{* *}$ & $-91.054^{* *}$ \\
& Monthly & $(1,1)$ & $3393.070^{* *}$ & $-80.258^{* *}$ \\
\hline Palladium & Daily & $(12,11)$ & $47.225^{* *}$ & $-9.717^{* *}$ \\
& Weekly & $(8,7)$ & $27.690^{* *}$ & $-7.441^{* *}$ \\
& Monthly & $(2,2)$ & $47.478^{* *}$ & $-9.727^{* *}$ \\
\hline Silver & Daily & $(11,12)$ & $61.001^{* *}$ & $-11.044^{* *}$ \\
& Weekly & $(6,7)$ & $55.696^{* *}$ & $-10.544^{* *}$ \\
& Monthly & $(10,1)$ & $1018.274^{* *}$ & $-44.604^{* *}$ \\
\hline
\end{tabular}

The test is conducted by comparing the F-statistic and t-statistic against the lower and the upper bounds for the asymptotic critical values. The bounds F-test is performed against the joint null hypothesis that the coefficients of the contemporaneous and lagged futures prices are collectively zero (i.e., no long-run equilibrium relationship between spot and futures prices) and the speed-of-adjustment coefficient is zero.

$$
\mathrm{H}_{0}^{\mathrm{F}}: \sum_{\mathrm{i}=0}^{\mathrm{q}} \beta_{\mathrm{i}}=0 \cap \Phi(1)=0
$$

If the F-statistic exceeds the upper bound, this indicates that there exists a long-run relationship between spot and futures prices; if the F-statistic is below the lower bound, there is no cointegration. If the F-statistic falls between the bounds, the test is inconclusive. As a supplemental test to confirm the validity of the abovementioned bounds F-test, a bounds t-test can be performed against the null hypothesis of zero speed-of-adjustment coefficient. If the test statistic is greater than the upper bound of the critical value, one concludes that there is a cointegrating relationship.

$$
\mathrm{H}_{0}^{\mathrm{t}}: \Phi(1)=0
$$




\subsection{Optimal Hedge Ratio Estimation}

The primary objective of this study is to examine the impact of cointegration between spot and futures prices on the hedge ratio estimate. This section therefore involves two contrasting approaches: the model that takes into account a long-run equilibrium relationship between two prices, and the one that does not. First, the results with the conventional OLS regression models are shown in Table 3. Panels A, B, and $C$ represent one-day, one-week, and one-month hedge horizons, respectively. The fourth column indicates the optimal hedge ratios estimated based on the first-differenced spot and futures prices (= $\left.\widehat{\beta}_{\text {OLS }}\right)$.

\section{Table 3: OLS Hedge Ratio Estimations with 1-Day, 1-Week, and 1-Month Hedge Horizons}

$a$ is the constant. $\widehat{\boldsymbol{\beta}}_{\mathrm{oLs}}$ is the coefficient of the current change in the futures price and represents the short-run hedge ratio. A single asterisk $\left({ }^{*}\right)$ and a double asterisk (**) indicate a significance level of $5 \%$ and $1 \%$, respectively, for the Wald tests on null hypotheses: $\mathrm{a}=0$ and $\boldsymbol{\beta}_{\mathrm{OLS}}=1$.

$$
\Delta \mathrm{S}_{t}=\alpha+\beta_{\mathrm{OLS}} \Delta \mathrm{F}_{t}+\varepsilon_{t}
$$

\begin{tabular}{|c|c|c|c|c|}
\hline $\begin{array}{l}\text { Panel A: One-Day Hedging } \\
\text { Commodity }\end{array}$ & Obs. & $\mathbf{a}$ & $\widehat{\boldsymbol{\beta}}_{\text {OLS }}$ & Adj. $R^{2}$ \\
\hline Gold & 2597 & 0.1805 & $0.4155^{* *}$ & 0.1745 \\
\hline Platinum & 2597 & -0.0014 & $0.6622 * *$ & 0.3997 \\
\hline Palladium & 2597 & 0.0638 & $0.4867^{* *}$ & 0.2300 \\
\hline Silver & 2597 & 0.0018 & $0.4765^{* *}$ & 0.1977 \\
\hline $\begin{array}{l}\text { Panel B: One-Week Hedging } \\
\text { Commodity }\end{array}$ & Obs. & $\mathbf{a}$ & $\widehat{\boldsymbol{\beta}}_{\text {OLS }}$ & Adj. $R^{2}$ \\
\hline Gold & 547 & 0.1994 & $0.8719 * *$ & 0.7754 \\
\hline Platinum & 547 & 0.0052 & $0.9619^{*}$ & 0.8786 \\
\hline Palladium & 547 & 0.0667 & $0.8917^{* *}$ & 0.7675 \\
\hline Silver & 547 & 0.0038 & $0.7418^{* *}$ & 0.6928 \\
\hline $\begin{array}{l}\text { Panel C: One-Month Hedging } \\
\text { Commodity }\end{array}$ & Obs. & $\mathbf{a}$ & $\widehat{\boldsymbol{\beta}}_{\text {OLS }}$ & Adj. $R^{2}$ \\
\hline Gold & 125 & 0.4213 & $0.9441^{*}$ & 0.9132 \\
\hline Platinum & 125 & 0.0445 & $0.9487^{* *}$ & 0.9637 \\
\hline Palladium & 125 & 0.0998 & 0.9752 & 0.9490 \\
\hline Silver & 125 & 0.0043 & $0.9370^{*}$ & 0.8887 \\
\hline
\end{tabular}

The Wald test conducted on the null hypothesis that the hedge ratio is equal to unity is rejected at a significance level of 0.05 or better for all the markets and hedge horizons, except for palladium with a one-month hedge period. Nevertheless, it is worthwhile to note that the OLS hedge ratio estimate, as well as adjusted R-squared, approaches unity as the length of the hedge period increases. This is consistent to the finding in Chen et al. (2004) based on different commodities and implies that, when more time for adjustments is given, the price-adjustment delays due to infrequent transactions become less prominent.

Table 4 presents a comparison between the OLD estimates of spot-futures hedge ratios and the ARDLadjusted hedge ratios. Consistent with Table 3, Panels A, B, and C represent one-day, one-week, and one-month hedge horizons, respectively. The third column indicates the model specifications; the optimal lag orders for spot prices $\left(=p^{*}\right)$ and futures prices $\left(=q^{*}\right)$ are determined with the AIC. The OLS hedge ratios shown in the fifth column ( $=\hat{\beta}_{\text {oLS }}$ ) are compared to the ARDL-adjusted estimate in the sixth column $\left(=\hat{\lambda}_{\mathrm{F}, 0}\right)$. The seventh and eighth columns indicate the long-run equilibrium relation between spot and futures prices $(=\theta)$ and the speed of adjustment toward the equilibrium $(=\Phi(1))$, respectively. 
Table 4: ARDL-Adjusted Hedge Ratio Estimations with 1-Day, 1-Week, and 1-Month Horizons

ARDL $\left(p^{*}, q^{*}\right)$ indicates the model specifications, where the optimal lag orders for the first-differenced spot price (= p*) and the first-differenced futures price $\left(=q^{*}\right)$ are determined with the Akaike Information Criterion (AIC). $\mathbf{c}_{\mathbf{0}}$ is the constant. $\hat{\boldsymbol{\lambda}}_{\mathbf{F}, \mathbf{0}}$ is the coefficient of the current change in the futures price and is considered the short-run hedge ratio. $\theta$ represents the long-run equilibrium relationship between spot and futures prices and $\Phi(1)$ is the speed of adjustment toward the equilibrium. A single asterisk $\left({ }^{*}\right)$ and a double asterisk $\left({ }^{* *}\right)$ indicate a significance level of $5 \%$ and $1 \%$, respectively, for the Wald tests on null hypotheses: $\mathbf{c}_{\mathbf{0}}=0, \boldsymbol{\beta}_{\mathrm{OLS}}=1, \boldsymbol{\lambda}_{\mathbf{F}, \mathbf{0}}=1$, and $\theta=1$.

$$
\Delta \mathrm{S}_{t}=\mathrm{c}_{0}+\mathrm{c}_{1} t+\sum_{\mathrm{i}=1}^{\mathrm{p}-1} \lambda_{\mathrm{S}, \mathrm{i}} \Delta \mathrm{S}_{t-\mathrm{i}}+\sum_{\mathrm{i}=0}^{\mathrm{q}-1} \lambda_{\mathrm{F}, \mathrm{i}} \Delta \mathrm{F}_{t-\mathrm{i}}+\Phi(1)\left(\mathrm{S}_{t-1}-\theta \mathrm{F}_{t-1}\right)+\mu_{t}
$$

\begin{tabular}{|c|c|c|c|c|c|c|c|c|}
\hline \multicolumn{9}{|c|}{ Panel A: One-Day Hedging } \\
\hline Commodity & Obs. & $\operatorname{ARDL}\left(p^{*}, q^{*}\right)$ & $\mathbf{c}_{\mathbf{0}}$ & $\widehat{\boldsymbol{\beta}}_{\text {OLS }}$ & $\hat{\lambda}_{\mathrm{F}, 0}$ & $\widehat{\boldsymbol{\theta}}$ & $\widehat{\Phi}(1)$ & Adj. $R^{2}$ \\
\hline Gold & 2586 & $(11,12)$ & -0.6933 & $0.4155^{* *}$ & $0.4020^{* *}$ & 1.0007 & -0.6654 & 0.7842 \\
\hline Platinum & 2586 & $(12,12)$ & -1.5159 & $0.6622 * *$ & $0.5994^{* *}$ & 1.0028 & -0.5136 & 0.7607 \\
\hline Palladium & 2586 & $(12,11)$ & $-2.7251^{* *}$ & $0.4867^{* *}$ & $0.4316^{* *}$ & $1.0155^{* *}$ & -0.3877 & 0.7685 \\
\hline Silver & 2586 & $(11,12)$ & -0.0233 & $0.4765^{* *}$ & $0.4799^{* *}$ & 1.0052 & -0.2963 & 0.6586 \\
\hline \multicolumn{9}{|c|}{ Panel B: One-Week Hedging } \\
\hline Commodity & Obs. & $\operatorname{ARDL}\left(p^{*}, q^{*}\right)$ & $\mathbf{c}_{0}$ & $\widehat{\boldsymbol{\beta}}_{\mathrm{OLS}}$ & $\hat{\lambda}_{\mathrm{F}, 0}$ & $\widehat{\boldsymbol{\theta}}$ & $\widehat{\Phi}(1)$ & Adj. $R^{2}$ \\
\hline Gold & 536 & $(12,5)$ & -1.2254 & $0.8719^{* *}$ & $0.8859 * *$ & 1.0010 & -1.2014 & 0.8995 \\
\hline Platinum & 536 & $(1,1)$ & -3.5989 & $0.9619^{*}$ & $0.9536^{* *}$ & 1.0037 & -0.9501 & 0.9398 \\
\hline Palladium & 536 & $(8,7)$ & $-5.0654^{* *}$ & $0.8917^{* *}$ & $0.8907^{* *}$ & $1.0153^{* *}$ & -0.7172 & 0.8919 \\
\hline Silver & 536 & $(6,7)$ & -0.0323 & $0.7418^{* *}$ & $0.7993^{* *}$ & 1.0023 & -0.9839 & 0.8470 \\
\hline \multicolumn{9}{|c|}{ Panel C: One-Month Hedging } \\
\hline Commodity & Obs. & $\operatorname{ARDL}\left(p^{*}, q^{*}\right)$ & $\mathbf{c}_{\mathbf{0}}$ & $\widehat{\boldsymbol{\beta}}_{\text {OLS }}$ & $\hat{\lambda}_{\mathrm{F}, \mathbf{0}}$ & $\widehat{\boldsymbol{\theta}}$ & $\widehat{\Phi}(1)$ & Adj. $R^{2}$ \\
\hline Gold & 114 & $(1,1)$ & 0.4352 & $0.9441^{*}$ & 0.9666 & 0.9988 & -1.1113 & 0.9610 \\
\hline Platinum & 114 & $(1,1)$ & 4.1674 & $0.9487^{* *}$ & $0.9426^{* *}$ & 0.9968 & -0.9456 & 0.9836 \\
\hline Palladium & 114 & $(2,2)$ & $-7.0151^{* *}$ & 0.9752 & $0.9583^{* *}$ & $1.0120 * *$ & -1.2917 & 0.9774 \\
\hline Silver & 114 & $(10,1)$ & 0.0296 & $0.9370 *$ & 1.0094 & 1.0002 & -1.0092 & 0.9499 \\
\hline
\end{tabular}

The ARDL-based model exhibits higher adjusted R-squared than the conventional OLS model does, regardless of the commodity or the hedge length. This is in line with expectation since an ARDL model includes additional variables (i.e., lagged futures prices). More interestingly, the comparison of the hedge ratio estimates highlights a clear contrast between actively-traded commodities and those that are not. For example, with respect to gold and silver, the ARDL-adjusted estimate is higher than that yielded in the corresponding OLS model with one-week or longer hedge periods. The ARDL-adjusted estimate of the one-week hedge ratio for gold (silver) is 0.8859 (0.7993), which is slightly higher than 0.8719 (0.7418) estimated with the OLS method. The difference between the hedge ratio estimates based on these two approaches is even greater with a one-month period; the ARDL estimate of gold (silver) hedge ratio, 0.9666 (1.0094), is substantially higher than the OLS estimate of 0.9441 (0.9370). Moreover, for both the commodities, the null hypothesis that the one-month ARDL hedge ratio is equal to unity cannot be rejected at a significance level of 0.05 . Overall, our analysis on gold and silver markets empirically supports Lien's (2004) proposition that the omission of a long-run cointegrating relationship between two prices leads to a smaller hedge ratio estimate.

In contrast, the ARDL-adjusted hedge ratio estimate for platinum and palladium are almost equal to or smaller than the corresponding OLS estimates. Because this trend is consistent regardless of the hedge horizon, the variation in the results must be rather associated with differences in futures markets. While the LBMA auction is only held once or twice a day, futures transactions occur virtually on a continuous basis throughout a day. Nevertheless, futures trading volumes significantly vary across commodities. As shown in Table 1, the average numbers of gold, silver, platinum, and palladium futures contracts 
transacted per day during the sample period are in the ratios of 35:12:2:1. These ratios provide a rough proxy of the differences in trading frequencies across futures markets, and it is clearly indicated that the platinum and palladium are far less frequently traded than gold or silver. The contrast in our findings suggests that statistical bias created by ignoring spot-futures cointegration (i.e., a disadvantage of the OLS model) may be observable only if futures contracts are actively traded.

\section{Conclusions}

Risk managers seeking to apply special hedge accounting treatment under the ASC Topic 815 must demonstrate higher hedge effectiveness while the exact regression design for prospective and retrospective effectiveness testing has been debated over years. This article aims to simultaneously examine two econometric issues causing Information inefficiency in the conventional OLS hedge ratio: cointegration between spot and futures prices and infrequent trading in spot market. We specifically utilize the data from the precious metal markets, where spot and futures contracts are traded at very different frequencies while their prices are mutually cointegrated. The ARDL bounds test procedure is used to test a long-run equilibrium relationship between spot and futures prices.

The result in our study demonstrates that, in the gold and silver markets, a hedge ratio estimated with a conventional OLS model tends to be lower than an ARDL-adjusted estimate. Our finding empirically supports that the omission of a long-term spot-futures equilibrium relationship leads to a downwardlybiased hedge ratio estimate. On the other hand, such statistical bias is not observed with respect to the platinum or palladium markets. The contrast in our findings indicates that whether omitted-variable bias in the presence of spot-futures cointegration can be observed depends on the liquidity in a futures market.

\section{Acknowledgements}

My paper has greatly benefited from the insightful comments of an anonymous referee. I also thank Don MacDonald for his helpful suggestions. All errors are my own.

\section{References}

Aulerich, N.M., Fishe, R.P. and Harris, J.H., 2011. Why do expiring futures and cash prices diverge for grain markets?. Journal of Futures Markets, 31 (6), 503-533.

Benet, B.A., 1992. Hedge period length and Ex-ante futures hedging effectiveness: The case of foreignexchange risk cross hedges. Journal of Futures Markets, 12 (2), 163-175.

Castelino, M.G., 1992. Hedge effectiveness: Basis risk and minimum-variance hedging. Journal of Futures Markets, 12(2), 187-201.

Chen, S.S., Lee, C.F. and Shrestha, K., 2004. An empirical analysis of the relationship between the hedge ratio and hedging horizon: A simultaneous estimation of the short-and long-run hedge ratios. Journal of Futures Markets: Futures, Options, and Other Derivative Products, 24 (4), 359-386.

Dimson, E., 1979. Risk measurement when shares are subject to infrequent trading. Journal of Financial Economics, 7(2), 197-226.

Ederington, L.H., 1979. The hedging performance of the new futures markets. The Journal of Finance, $34(1), 157-170$. 
Engle, R.F. and Granger, C.W., 1987. Co-integration and error correction: representation, estimation, and testing. Econometrica: journal of the Econometric Society, 251-276.

Ghosh, A., 1993. Hedging with stock index futures: Estimation and forecasting with error correction model. Journal of Futures Markets, 13(7), 743-752.

Granger, C.W., 1981. Some properties of time series data and their use in econometric model specification. Journal of econometrics, 16(1), 121-130.

Howard, C.T. and D'Antonio, L.J., 1991. Multiperiod hedging using futures: A risk minimization approach in the presence of autocorrelation. Journal of Futures Markets, 11 (6), 697-710.

Johansen, S., 1988. Statistical analysis of cointegration vectors. Journal of economic dynamics and control, 12(2-3), 231-254.

Johnson, L.L., 1960. The theory of hedging and speculation in commodity futures. The Review of Economic Studies, 27(3), 139-151.

Juhl, T., Kawaller, I.G. and Koch, P.D., 2012. The effect of the hedge horizon on optimal hedge size and effectiveness when prices are cointegrated. Journal of Futures Markets, 32 (9), 837-876.

Kroner, K.F. and Sultan, J., 1993. Time-varying distributions and dynamic hedging with foreign currency futures. Journal of financial and quantitative analysis, 28(4), 535-551.

Lien, D., 2004. Cointegration and the optimal hedge ratio: the general case. The Quarterly review of economics and finance, 44(5), 654-658.

Lo, A.W. and MacKinlay, A.C., 1990. An econometric analysis of nonsynchronous trading. Journal of Econometrics, 45(1-2), 181-211.

Luoma, M., Martikainen, T. and Perttunen, J., 1993. Thin trading and estimation of systematic risk: an application of an error-correction model. Annals of Operations Research, 45 (1), 297-305.

Myers, R.J. and Thompson, S.R., 1989. Generalized optimal hedge ratio estimation. American Journal of Agricultural Economics, 71 (4), 858-868.

Narayan, P.K., 2005. The saving and investment nexus for China: evidence from cointegration tests. Applied economics, 37(17), 1979-1990.

Pesaran, M.H. and Shin, Y., 1998. An autoregressive distributed-lag modelling approach to cointegration analysis. Econometric Society Monographs, 31, 371-413.

Pesaran, M.H., Shin, Y. and Smith, R.J., 2001. Bounds testing approaches to the analysis of level relationships. Journal of applied econometrics, 16(3), 289-326.

Scholes, M. and Williams, J., 1977. Estimating betas from nonsynchronous data. Journal of financial economics, 5(3), 309-327.

Viswanath, P.V., 1993. Efficient use of information, convergence adjustments, and regression estimates of hedge ratios. Journal of Futures Markets, 13(1), 43-53.

Wilkinson, K.J., Rose, L.C. and Young, M.R., 1999. Comparing the effectiveness of traditional and time varying hedge ratios using New Zealand and Australian debt futures contracts. Financial Review, 34 (3), 79-94 